\title{
Prolonged oxytocin treatment in rats affects intracellular signaling and induces myocardial protection against infarction
}

\author{
Maria Ondrejcakova ${ }^{1}$, Miroslav Barancik ${ }^{2}$, Monika Bartekova ${ }^{2}$, Tana Ravingerova ${ }^{2}$ and Daniela \\ Jezova $^{1}$ \\ ${ }^{1}$ Institute of Experimental Endocrinology, Slovak Academy of Sciences, Bratislava, Slovak Republic \\ ${ }^{2}$ Institute for Heart Research, Slovak Academy of Sciences, Bratislava, Slovak Republic
}

\begin{abstract}
Oxytocin is a hormone, which is released into the circulation in response to acute or chronic stress stimuli. One of the important targets of oxytocin is cardiovascular system. Present studies were aimed at testing the hypothesis that prolonged treatment with oxytocin (simulation of stress-induced rise in circulating oxytocin) activates intracellular signaling pathways playing a role in ischemia/reperfusion injury. Furthermore, we tested protective effects of oxytocin treatment in vivo against cardiac injury induced by ischemia/reperfusion of isolated hearts. Male Wistar rats were treated with oxytocin or vehicle continuously via osmotic minipumps for 2 weeks. The hearts were used for biochemical measurements or isolated for Langendorff perfusion. Treatment with oxytocin resulted in a significant increase in specific phosphorylation (activation) of p38-MAPK and Akt kinase, an increase in phosphorylated Hsp27 and an elevation in atrial natriuretic peptide (ANP) levels in left ventricular heart tissue. There were no significant changes in the activation of MMP-2 and ERK in the left heart ventricle of oxytocin-treated rats. Postischemic recovery of functional parameters LVDP, RPP, $+\mathrm{dP} / \mathrm{dtmax}$ and $-\mathrm{dP} / \mathrm{dtmax}$ was better in the hearts of oxytocin-treated rats compared to that in the controls. Oxytocin treatment significantly reduced infarct size to 15.1 $+3.2 \%$ as compared to $32.4+3.5 \%$ in vehicle-treated rats $(p<0.01)$. This is the first evidence for cardioprotective effects of oxytocin administered in vivo simulating chronic stress-induced elevation in plasma oxytocin. The present results show that positive effects of oxytocin that may ameliorate negative consequences of stress on the heart are, at least in part, mediated through p38-MAPK and Akt kinase pathways.
\end{abstract}

Key words: Oxytocin - Stress - Myocardial infarction - Protein kinases

\begin{abstract}
Abbreviations: ANP, atrial natriuretic peptide; $\mathrm{CF}$, coronary flow; ERK, extracellular signal-regulated protein kinase; $H R$, heart rate; $H$ sp, heat shock protein; IS, infarct size; LVDP, left ventricular developed pressure; LVEDP, left ventricular end-diastolic pressure; MAPK , mitogen-activated protein kinase; MMP, matrix metalloproteinase; PI3K, phosphatidylinositol-3 kinase; RPP, rate-pressure product.
\end{abstract}

\section{Introduction}

Oxytocin may be considered a typical stress hormone responding to several acute and chronic stress stimuli and

Correspondence to: Daniela Jezova, Laboratory of Pharmacological Neuroendocrinology, Institute of Experimental Endocrinology, Slovak Academy of Sciences, Vlarska 3, Bratislava 83306, Slovak Republic

E-mail: daniela.jezova@savba.sk has a great array of physiological activities in the periphery (Jezova et al. 1995; Ondrejcakova et al. 2010). Cardiovascular system belongs to important targets of oxytocin action that is supported by the presence of oxytocin receptors in the heart (Gutkowska et al. 1997) and vascular endothelial cells (Thibonnier et al. 1999; Jankowski et al. 2000). Cardiovascular effects of oxytocin include its influence on blood pressure (Costa-E-Sousa et al. 2005; Bakos et al. 2008), heart rate and contractility (Ondrejcakova et al. 2009). Moreover, in agreement with described protective action of oxytocin on 
renal and liver tissue injury (Tuğtepe et al. 2007; Düşünceli et al. 2008), we have shown that oxytocin exerts beneficial effects on myocardial injury induced by ischemia/reperfusion in isolated rat heart (Ondrejcakova et al. 2009). This finding was supported by the data of Houshmand et al. (2009) who used acute in situ treatment with oxytocin in anesthetized rats. The mechanisms responsible for cardioprotective action of oxytocin are not understood. So far, the involvement of negative chronotropic action of oxytocin (Ondrejcakova et al. 2009) and activation of mitochondrial ATP-dependent potassium channels (Alizadeh et al. 2010) has been suggested. Oxytocin treatment prior to myocardial infarction can modify several other pathways playing a role in ischemia/reperfusion injury, such as enzyme systems of protein kinases (Ravingerova et al. 2003; Simoncikova et al. 2008). For example, an association between increased activation of some mitogen-activated protein kinases (MAPKs) and cardioprotection has been proposed (Yue et al. 2002) and the cascade of phosphatidylinositol-3 kinase (PI3K)/Akt is known for its antiapoptotic effects (Miyamoto et al. 2009). The aim of the present studies was to test the hypothesis that simulation of stress-induced rise in circulating oxytocin (treatment with oxytocin for two weeks) stimulates selected intracellular signaling pathways in the myocardial tissue. Furthermore, we have verified the hypothesis that prolonged treatment with oxytocin in vivo exerts protective effects against cardiac injury induced by ischemia/reperfusion.

\section{Materials and Methods}

\section{Animals}

Adult male Wistar (350-490 g) rats (AnLab s.r.o., Prague, Czech Republic), were used in this study. They were kept under standard housing conditions with a constant 12:12 h light/dark cycle (lights on at $06.00 \mathrm{~h}$ ) and temperature $\left(22 \pm 2{ }^{\circ} \mathrm{C}\right)$. Food and water were available ad libitum. Principles of laboratory animal care and all procedures were approved by the Animal Health and Animal Welfare Division of the State Veterinary and Food Administration of the Slovak Republic and conformed to the NIH Guidelines for the Care and Use of Laboratory Animals.

\section{Treatment and implantation of osmotic minipumps}

The animals were randomly assigned to vehicle- $(n=15)$, and oxytocin-treated groups $(n=17)$. Oxytocin (Oxytocin, H-2510, Bachem, Switzerland) or vehicle (saline) were continuously administered via osmotic minipumps (Model 2002, Alzet, Alza Corp., USA) for 2 weeks. Implantation of osmotic minipumps was carried out under combined ketamine (Narkamon 5\%, $1.2 \mathrm{ml} / \mathrm{kg}$ ) and xylazine (Rome$\operatorname{tar} 2 \%, 0.4 \mathrm{ml} / \mathrm{kg}$ ) anesthesia. Minipumps were implanted subcutaneously as described previously (Hlavacova and Jezova 2008; Eckertova et al. 2011). Following implantation of osmotic minipumps, the rats were housed individually. The minipumps delivered oxytocin at the dose of $3.6 \mu \mathrm{g} /$ $100 \mathrm{~g}$ body weight/day. Oxytocin was dissolved in isotonic saline. Control animals received minipumps that contained vehicle only.

\section{Experimental protocols}

On the 14th day following minipumps implantation, vehicle- $(n=8)$ and oxytocin-treated $(n=8)$ rats were killed by decapitation in the morning between 10.00-12.00 h. Heart ventricles were quickly removed, frozen in liquid nitrogen and stored at $-70^{\circ} \mathrm{C}$ until use.

Other groups of animals treated with vehicle $(n=7)$ and oxytocin $(n=9)$ were anesthetized, hearts were rapidly excised, placed in ice-cold perfusion buffer and mounted on the perfusion apparatus for the investigation of the physiological parameters. The hearts were perfused for an initial 15-min stabilization period (baseline) and subjected to 25 min of global ischemia followed by reperfusion. Contractile parameters of the heart function were measured until $40 \mathrm{~min}$ of reperfusion which lasted $120 \mathrm{~min}$. Thereafter the hearts were processed for the infarct size determination.

\section{Perfusion technique}

The hearts were cannulated via the aorta and perfused in the Langendorff mode at a constant perfusion pressure as described previously (Ondrejcakova et al. 2009). Shortly, the perfusion solution was a modified Krebs-Henseleit buffer gassed with $95 \% \mathrm{O}_{2}$ and $5 \% \mathrm{CO}_{2}$ (pH 7.4). Heart rate (HR) was calculated from the epicardial electrogram, which was continuously recorded (Mingograph ELEMASiemens, Solna, Sweden). Coronary flow was measured by a collection of coronary effluent. Left ventricular pressure was measured by means of a latex water-filled balloon inserted into the left ventricle (adjusted to obtain diastolic pressure of 5-7 $\mathrm{mmHg}$ ) and connected to a pressure transducer (P23 Db Pressure Transducer, Gould Statham Instruments, USA). Left ventricular developed pressure (LVDP, systolic minus diastolic pressure), left ventricular end-diastolic pressure (LVEDP), maximal rates of pressure development and fall $\left(+\mathrm{dP} / \mathrm{dt}_{\max }\right.$ and $\left.-\mathrm{dP} / \mathrm{dt}_{\max }\right)$ as the indexes of contraction and relaxation, rate-pressure product (RPP, LVDP x HR) as well as the HR and coronary flow (CF) were used to assess cardiac function. Postischemic recovery of function after ischemia/reperfusion was expressed as percentage of preischemic baseline values or in absolute values $(\mathrm{mmHg})$ for LVEDP. 


\section{Infarct size determination}

The infarct size was visualized by staining with 2,3,5-triphenyl-tetrazolium chloride (1\%; Sigma, St. Louis, MO, USA) and determined by a computerized planimetric method as described previously (Ondrejcakova et al. 2009). The infarct size (IS) area was normalized to the size of the left ventricle (LV) area (IS/LV) and expressed as percentage. The mean value of IS/LV in all sections in one heart was treated as one value and used for group statistics.

\section{Preparation of protein fractions}

The tissues from LV of control and oxytocin-treated rats were resuspended in ice-cold homogenization buffer containing $20 \mathrm{mmol} / \mathrm{l}$ Tris- $\mathrm{HCl}, 250 \mathrm{mmol} / \mathrm{l}$ sucrose, $1.0 \mathrm{mmol} / \mathrm{l}$ EGTA, $1.0 \mathrm{mmol} / \mathrm{l}$ dithiothreitol (DTT), $1.0 \mathrm{mmol} / \mathrm{l}$ phenylmethylsulfonylfluoride (PMSF) and $0.5 \mathrm{mmol} / 1$ sodium orthovanadate (resulting $\mathrm{pH}$ 7.4) and homogenized with a Teflon glass homogenizer. The homogenates were centrifuged at $800 \times g$ for $5 \mathrm{~min}$ at $4^{\circ} \mathrm{C}$ and the supernatants were centrifuged again at $16,100 \times g$ for $30 \mathrm{~min}$. The final supernatants representing soluble fraction were used for further analysis. The protein concentrations were measured by the method of Bradford (1976). Quantification of protein levels and/or activation was done using Phosphorimager Thyphoon (Amersham Biosciences).

\section{Electrophoresis and immunochemical Western blot analysis}

Samples of protein fractions containing equivalent amounts of proteins per lane were separated by sodium dodecyl sulfate-polyacrylamide gel electrophoresis (SDS-PAGE). After electrophoretic separation, proteins were transferred to nitrocellulose membrane for Western blot assays. The quality of transfer was controlled by Ponceau S staining of nitrocellulose membranes after transfer and protein loading was controlled using glyceraldehyde-3-phosphate dehydrogenase (GAPDH) as a housekeeper. After incubation of membranes with specific primary and secondary antibodies, the bound antibodies were detected by enhanced chemiluminescence (ECL) method.

Specific primary and secondary antibodies used for immunodetection of proteins were obtained from Santa Cruz Biotechnology (anti-ERK-2: rabbit polyclonal, anti-p38MAPK: rabbit polyclonal, anti-Akt: rabbit polyclonal, antiGAPDH: rabbit polyclonal, anti-MMP-2: rabbit polyclonal), Cell Signaling Biotechnology (anti-phospho-ERK: rabbit polyclonal (Thr202/Tyr204), anti-phospho-p38-MAPK: rabbit polyclonal (Thr180/Tyr182), anti-phospho-Akt: rabbit polyclonal (Ser473), anti-phospho-Hsp27: rabbit polyclonal (Ser82), peroxidase-labelled anti-rabbit imunoglobulin) and Chemicon International(anti-ANP: rabbit polyclonal). In the case of enzymes, both non-phosporylated and phosphorylated forms were determined. The ratio between the levels of phosphorylated and non-phosphorylated forms reflects the activation of the enzyme.

\section{Measurement of matrix metalloproteinase (MMP) activities by gelatin zymography}

The gelatinolytic activities of MMP were determined by the modified method of Schönbeck et al. (1997). Laemmli buffer without 2-mercaptoethanol in proportion 1:1 was added to protein samples and non-heated samples were subjected to electrophoresis on $10 \%$ SDS-polyacrylamide gels co-polymerized with gelatin $(2 \mathrm{mg} / \mathrm{ml})$. After electrophoresis, gels were washed twice for $20 \mathrm{~min}$ each with $50 \mathrm{mmol} / \mathrm{l}$ Tris- $\mathrm{HCl}(\mathrm{pH}$ 7.4 ), containing $2.5 \%$ Triton $\mathrm{X}-100$, at $25^{\circ} \mathrm{C}$. After washing, the gels were incubated overnight at $37^{\circ} \mathrm{C}$ in substrate buffer containing $50 \mathrm{mmol} / \mathrm{l}$ Tris- $\mathrm{HCl}, 10 \mathrm{mmol} / \mathrm{l} \mathrm{CaCl} \mathrm{CaC}_{2}$ and $1.25 \%$ Triton $\mathrm{X}-100, \mathrm{pH}$ 7.4. After this incubation, the gels were stained with $1 \%$ Coomassie Brilliant Blue G-250, resolved in mixture of methanol : acetic acid : water (4:1:5) at room temperature for 2 hours and then destained with $40 \%$ methanol and $10 \%$ acetic acid. Gelatinolytic activities of matrix metalloproteinase-2 (MMP-2) were detected as transparent bands against dark blue background.

\section{Statistical evaluation}

Two-way analysis of variance (ANOVA) for repeated measures or Student's $t$-test were used for comparison of differences in variables among the groups (treatment). Data were expressed as means \pm SEM. Differences were considered significant at $p \leq 0.05$.

\section{Results}

\section{Influence of oxytocin treatment on MAPKs signaling pathways}

Analysis with an antibody specific for p38-MAPK showed that prolonged release of oxytocin via osmotic minipumps failed to influence protein levels of cytosolic p38-MAPK in the left heart ventricle (Fig. 1A). However, treatment with oxytocin resulted in a significant increase $(p<0.05)$ in specific phosphorylation (activation) of cytosolic p38-MAPK in left ventricular heart tissue (Fig. 1B,C). The activation of $\mathrm{p} 38$-MAPK pathway was confirmed also by the determination of phosphorylated Hsp27, a physiological substrate for MAP kinase-activated protein kinase 2, which is activated by $\mathrm{p} 38$-MAPK. Phosphorylated Hsp27 in the left ventricular tissue was significantly increased $(p<0.05)$ in the hearts of oxytocin-treated animals (Fig. 2A,B,C). 
Analysis of extracellular signal-regulated protein kinases (ERKs), other members of MAPKs signaling, showed that oxytocin treatment failed to influence both protein levels and activation of ERKs in left heart ventricular tissue (data not shown).

\section{Influence of oxytocin on PI3K/Akt signaling pathway}

Analysis with the antibody specific for Akt kinase revealed no differences in the levels of Akt kinase in the left heart ventricle between oxytocin- and vehicle-treated rats (Fig. $3 \mathrm{~A})$. On the other hand, detection with a phosphospecific

A

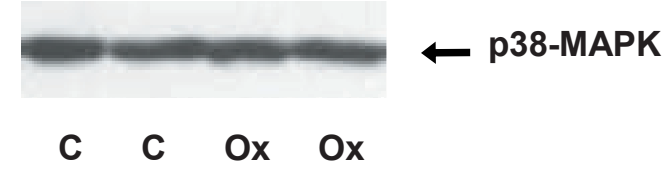

B

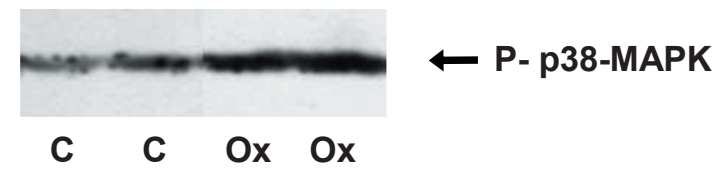

C

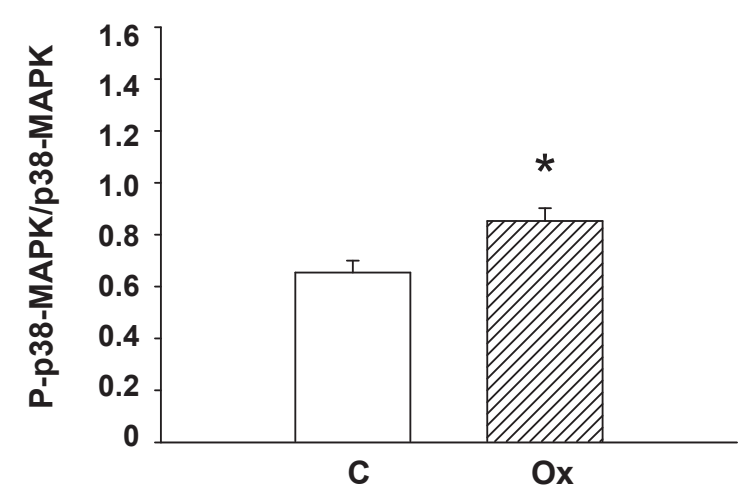

Figure 1. Influence of oxytocin on p38-MAPK signaling pathway. A. Western blot record showing protein levels of cytosolic p38MAPK in the left heart ventricle of control and oxytocin-treated rats. The arrow on the right shows the position of p38-MAPK. B. The changes in specific phosphorylation of cytosolic p38-MAPK in the left heart ventricle of control and oxytocin-treated rats. The p38-MAPK activation was determined using dual phospho-specific antibody (Thr180/Tyr 182). The arrow on the right shows the position of activated enzyme. C. The quantification of cytosolic p38MAPK phosphorylation in the left heart ventricle of control and oxytocin-treated rats. Data were obtained from Western blot records and are expressed as a ratio of the amount of phosphorylated, activated $\mathrm{p} 38$-MAPK to total $\mathrm{p} 38$-MAPK. Each bar represents mean \pm SEM. ${ }^{\star} p<0.05 v s$. control group. C, control group; Ox, oxytocintreated group; P-p38-MAPK, phosphoprylated p38-MAPK.

antibody (Ser473) showed increased activation of Akt kinase (Fig. 3B,C) in left ventricular heart tissue of oxytocin-treated rats as compared with untreated controls $(p=0.05)$.

\section{Influence of oxytocin treatment on atrial natriuretic peptide}

Prolonged exposure of rats to the action of oxytocin led to an increase in the levels of atrial natriuretic peptide (ANP) in the left ventricular heart tissue of oxytocin-treated animals (Fig. 4 A,B) compared with vehicle-treated group $(p<0.05)$.

A

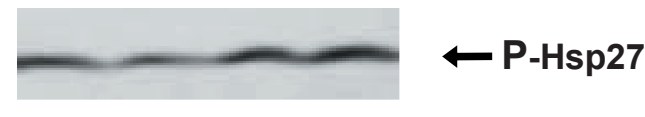

C C Ox Ox

B

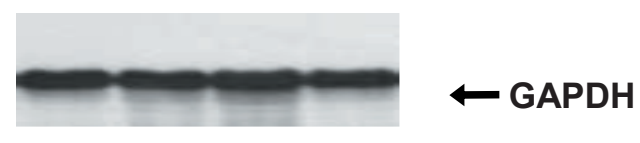

C C Ox Ox

C

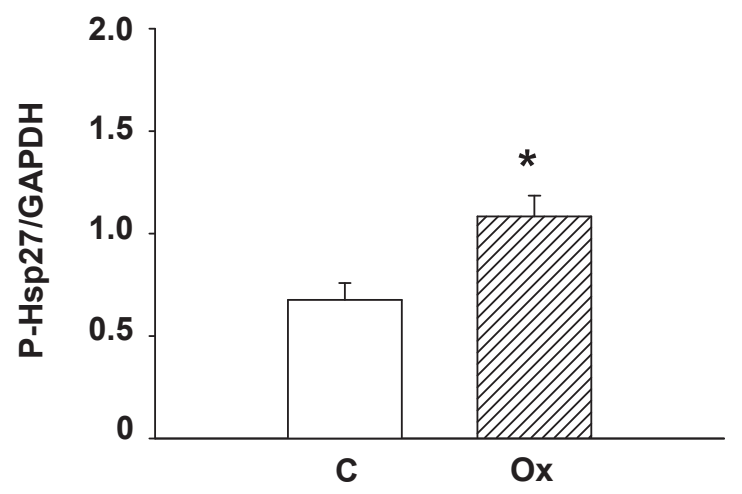

Figure 2. Influence of oxytocin on phosphorylation of Hsp27. A. Western blot record showing levels of cytosolic specific (Ser82) phosphorylated Hsp27 (P-Hsp27) in the left heart ventricle of control and oxytocin-treated rats. The arrow on the right shows the position of P-Hsp27. B. Record showing the protein levels of cytosolic glyceraldehyde-3-phosphate dehydrogenase (GAPDH) in the left heart ventricle of control and oxytocin-treated rats. C. The quantification of cytosolic Hsp27 phosphorylation in the left heart ventricle of control and oxytocin-treated rats. Western blot data obtained for P-Hsp27 were normalized to the levels of GAPDH (housekeeper). Each bar represents mean \pm SEM. ${ }^{\star} p<0.05$ oxytocin-treated $v s$. control group. For abbreviations see Fig. 1. 


\section{Influence of oxytocin treatment on MMP-2}

The effects of oxytoxin on protein levels of MMP-2 were determined using antibody that detects $63 \mathrm{kDa}$ (active MMP-2) and $72 \mathrm{kDa}$ (pro-MMP-2) forms of MMP-2. There were no differences in protein levels of MMP-2 in left heart ventricular tissue between the control and oxytocin-treated rats (data not shown). MMPs activities evaluated by zymographic analysis in polyacrylamide gels containing gelatin as a substrate, showed mainly the enzymatic gelatinolytic

A

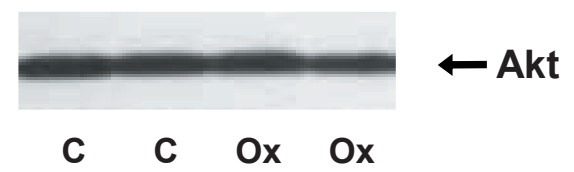

B

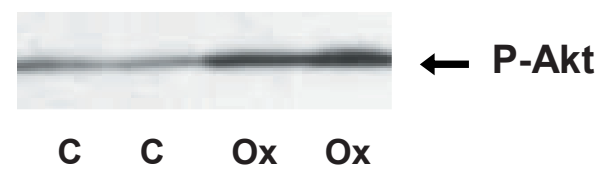

C

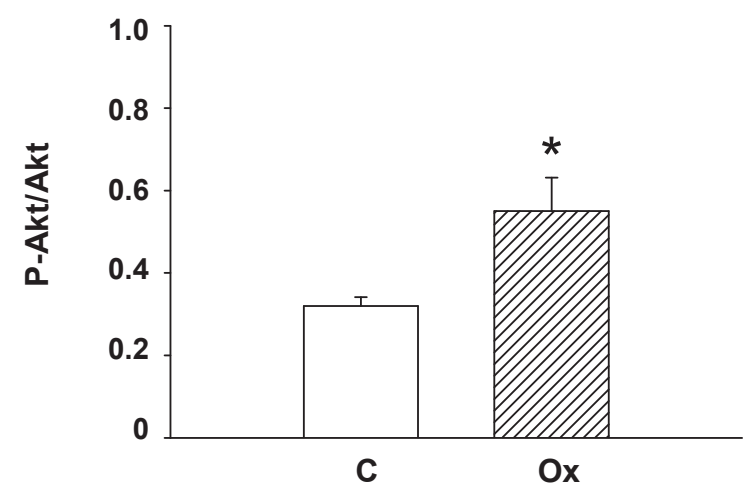

Figure 3. Influence of oxytocin on PI3K/Akt kinase signaling pathway. A. Western blot record showing protein levels of cytosolic Akt kinase in the left heart ventricle of control and oxytocin-treated rats. The arrow on the right shows the position of Akt kinase. B. The changes in specific phosphorylation of cytosolic Akt kinase in the left heart ventricle of control and oxytocin-treated rats. The Akt kinase activation was determined using phospho-specific antibody (Ser473). The arrow on the right shows the position of this activated enzyme. C. The quantification of cytosolic Akt kinase phosphorylation in the left heart ventricle of control and oxytocin-treated rats. Data were obtained from Western blot records and are expressed as a ratio of amount of phosphorylated, activated Akt kinase to total Akt kinase. Each bar represents mean \pm SEM. ${ }^{*} p=0.05 v s$. control group. P-Akt, phosphorylated Akt kinase. For other abbreviations see Fig. 1. activity of $72 \mathrm{kDa}$ form of pro-MMP-2. Similarly, there were no significant differences in the activities of MMP-2 in left heart ventricle of oxytocin-treated rats compared to those in the controls (data not shown).

\section{Influence of oxytocin treatment on physiological parameters of the isolated heart}

Physiological parameters of the hearts prior to ischemia are summarized in Table 1. There were no significant differences in baseline functional parameters between the groups.

Postischemic recovery of LVDP (Fig. 5A) and RPP (Fig. 5B) was better in the hearts of oxytocin-treated rats compared to their timecourse in the controls. Statistical analysis by two-way Anova for repeated measures revealed significantly higher values of $\operatorname{LVDP}\left(\mathrm{F}_{(1,14)}=7.35, p<\right.$ 0.05 for factor group) and $\operatorname{RPP}\left(\mathrm{F}_{(1,14)}=5.1397, p<0.05\right.$ for factor group) in oxytocin-treated animals compared
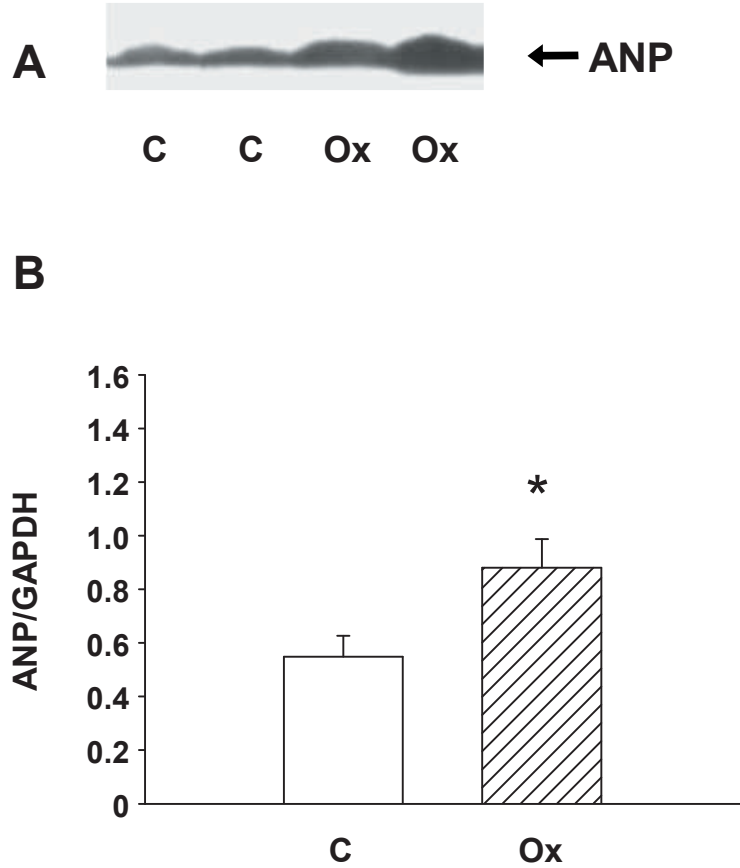

Figure 4. Influence of oxytocin on protein levels of atrial natriuretic peptide (ANP). A. Western blot record showing protein levels of cytosolic ANP in the left heart ventricle of control and oxytocin-treated rats. The arrow on the right shows the position of ANP. B. The quantification of cytosolic ANP protein levels in the left ventricular heart tissue of control and oxytocin-treated rats. Western blot data obtained for ANP were normalized to levels of GAPDH (housekeeper). Each bar represents mean \pm SEM. ${ }^{\star} p<0.05$ oxytocin-treated $v s$. control group. For abbreviations see Fig. 1. 
to those in controls. Similarly, maximal postischemic recovery of $+\mathrm{dP} / \mathrm{dt}_{\max }$ and $-\mathrm{dP} / \mathrm{dt}_{\max }$ measured at $40 \mathrm{~min}$ of reperfusion was significantly higher $(p<0.05)$ in the hearts of oxytocin-treated rats compared to that in the controls (Fig. 5C,D).

After ischemia, the values of LVEDP were significantly lower $(p<0.05)$ in the hearts of oxytocin-treated animals compared to those in the controls during the initial $40 \mathrm{~min}$ utes of reperfusion period (Fig. 6A). Statistical analysis by two-way ANOVA for repeated measures revealed a statistical significant effect $\left(\mathrm{F}_{(1,14)}=5.6, p<0.05\right.$ for factor group). There were no differences in CF recovery between the hearts of oxytocin- and vehicle-treated rats during reperfusion (data not shown).
Influence of oxytocin treatment on the size of infarction in the isolated heart

The effect of oxytocin treatment on the size of infarction induced by ischemia/reperfusion is shown in Fig. 6B. Pretreatment of rats with oxytocin significantly reduced infarct size to $15.1 \pm 3.2 \%$ as compared to $32.4 \pm 3.5 \%$ in vehicletreated rats $(p<0.01)$.

\section{Discussion}

The results of the present study show that two-week treatment with oxytocin activates intracellular PI3K/Akt kinase

A
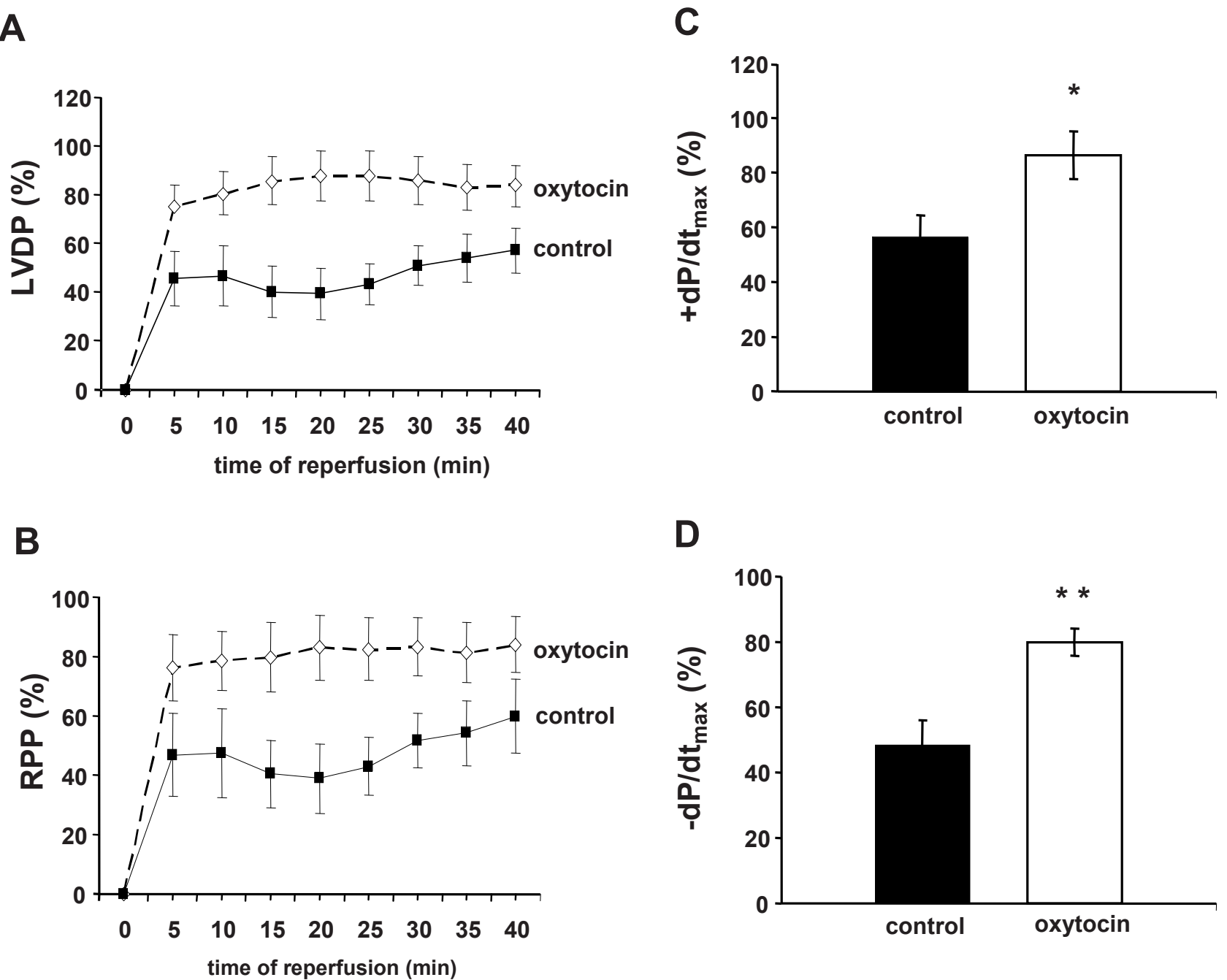

Figure 5. Effect of oxytocin on postischemic recovery of heart contractile function. A. Timecourse of left ventricular developed pressure (LVDP) recovery, in \% of baseline values. B. Timecourse of rate-pressure product (RPP) recovery, in \% of baseline values. C. Maximal rates of pressure development $\left(+\mathrm{dP} / \mathrm{dt}_{\max }\right)$ at 40 min of reperfusion, in $\%$ of baseline values. D. Maximal rates of pressure fall $\left(-\mathrm{dP} / \mathrm{dt}_{\max }\right)$ at $40 \mathrm{~min}$ of reperfusion, in $\%$ of baseline values. Data are means \pm SEM. ${ }^{\star} p<0.05,{ }^{\star *} p<0.01$ s. control group. For other abbreviations see Fig. 1. 
Table 1. Preischemic functional parameters of the isolated perfused rat heart of oxytocin-treated rats and control animals

\begin{tabular}{lcrcccccc}
\hline Group & $\begin{array}{c}\mathrm{HR} \\
(\mathrm{bpm})\end{array}$ & $\begin{array}{c}\mathrm{CF} \\
(\mathrm{ml} / \mathrm{min})\end{array}$ & $\begin{array}{c}\text { LVEDP } \\
(\mathrm{mmHg})\end{array}$ & $\begin{array}{c}\text { LVDP } \\
(\mathrm{mmHg})\end{array}$ & $\begin{array}{c}\mathrm{RPP} \\
(\mathrm{bpm} \times \mathrm{mmHg})\end{array}$ & $\begin{array}{c}-\mathrm{dP} / \mathrm{dtmax} \\
(\mathrm{mmHg} / \mathrm{s})\end{array}$ & $\begin{array}{c}+\mathrm{dP} / \mathrm{dtmax} \\
(\mathrm{mmHg} / \mathrm{s})\end{array}$ & $\begin{array}{l}n \\
\text { Control }\end{array}$ \\
$264 \pm 12$ & $15 \pm 1.2$ & $3.5 \pm 0.2$ & $85.5 \pm 7.5$ & $22731 \pm 2398$ & $2862 \pm 148$ & $3309 \pm 390$ & 9 \\
Oxytocin-treated & $263 \pm 17$ & $15.2 \pm 1.4$ & $3.8 \pm 0.3$ & $78.1 \pm 7.3$ & $20811 \pm 2623$ & $2691 \pm 145$ & $3337 \pm 414$ & 7 \\
\hline
\end{tabular}

CF, coronary flow; HR, heart rate; LVDP, left ventricular developed (systolic minus diastolic) pressure; LVEDP, left ventricular enddiastolic pressure; $-\mathrm{dP} / \mathrm{dtmax}$, maximal rate of pressure fall; $+\mathrm{dP} / \mathrm{dtmax}$, maximal rate of pressure development; RPP, rate pressure product. Data are means \pm SEM.

and p38-MAPK signaling pathways in the left heart ventricle as demonstrated by enhanced specific phosphorylation of p38-MAPK, Hsp27 and Akt kinase. In addition, increased levels of ANP were observed in the left heart ventricle of oxytocin-treated rats. Oxytocin treatment failed to influence activities of ERKs. Importantly, reduced size of infarction induced by ischemia/reperfusion and improved postischemic cardiac functional recovery were observed in rats treated with oxytocin for two weeks.

Increased Akt kinase phosphorylation indicates that prolonged increase in circulating oxytocin results in an activation of PI3K/Akt signaling pathway. The information on modulatory effects of oxytocin on this signaling pathway is scarce. In human umbilical vein endothelial cells, incubation with oxytocin led to increased Akt kinase phosporylation (Cattaneo et al. 2008). The PI3K/Akt pathway has been suggested to be involved in the oxytocin effects on the process of angiogenesis (Cattaneo et al. 2009). In the heart, PI3K/Akt signaling pathway was found to play an important role in responses of the heart to ischemia/reperfusion and in the mechanisms of heart adaptation to pathological situations (Hauselnoy et al. 2004; Strniskova et al. 2006; Spanikova et al. 2010). Moreover, PI3K/Akt kinase cascade is implicated in the processes of cell survival and metabolic control, and its activation was also found to play a role in infarct sizelimiting mechanisms in the rat heart (Ravingerova et al. 2007). In spite of this knowledge, possible effects of oxytocin on this pathway in the heart are unknown. The only study available demonstrated an increase in phosphorylated Akt kinase in the hearts of rats injected with oxytocin postinfarction on day 2 and 14 (Kobayashi et al. 2009). The present study demonstrates that prolonged treatment with oxytocin activates PI3K/Akt kinase cascade in the healthy heart which can explain cardioprotective effects of oxytocin observed previously following acute administration before ischemia in isolated hearts (Ondrejcakova et al. 2009) or anesthetized rats (Alizadeh et al. 2010) as well as following prolonged administration of oxytocin via minipumps found in the present experiments.

Presented data further show an activation of p38-MAPK pathway reflected by elevated levels of phosphorylated p38MAPK and Hsp27 proteins in the left heart ventricle induced by prolonged treatment with oxytocin. The role of $\mathrm{p} 38$ MAPK in ischemia/reperfusion injury is rather controversial (Barancik et al. 2000; Ravingerova et al. 2003), however, some

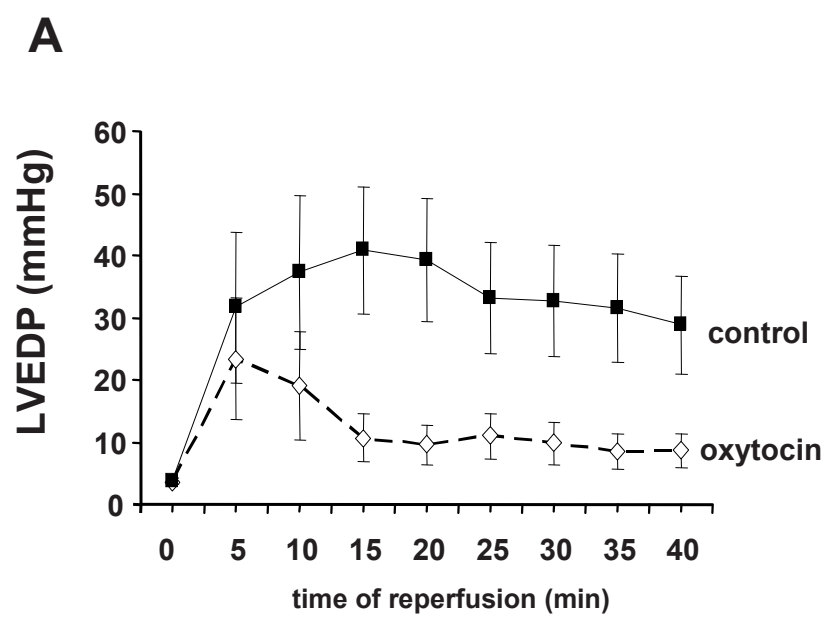

B

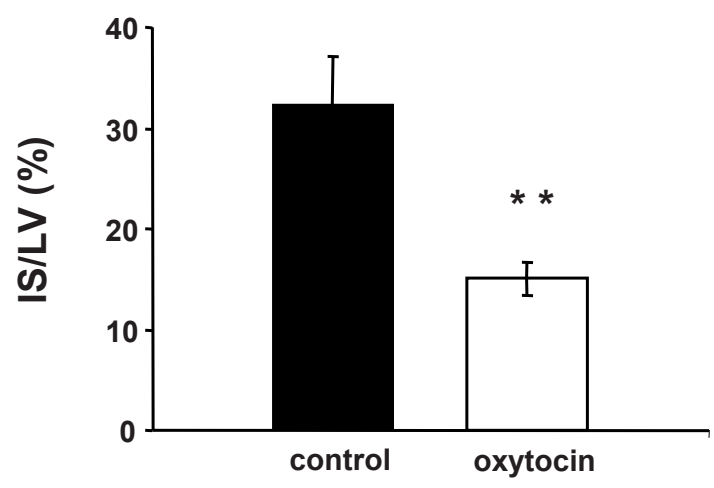

Figure 6. Effect of oxytocin on postischemic diastolic dysfunction and lethal myocardial injury. A. Timecourse of recovery of LVEDP. B. Effect of oxytocin on the size of myocardial infarction after 25-min global ischemia and 120-min reperfusion. Infarct size (IS) was normalized to the size of area at risk (LV) and expressed as percentage. Data are means \pm SEM. ${ }^{* *} p<0.01 v$ s. control group. For other abbreviations see Fig. 1. 
studies demonstrated the beneficial role of its activation in the mechanisms of cardioprotection in rats (Mocanu et al. 2000). To our knowledge, no information is available on oxytocin influence on p38-MAPK in the heart. Increased activation or no influence of oxytocin on p38-MAPK signaling was described in myometrial or endometrial cells in vitro (Burns et al. 2001; Devost et al. 2008). The activation of p38-MAPK can lead to the phosphorylation of small heatshock protein Hsp27. With regard to this protein, a study using immunoblotting detected marked changes in Hsp27 phosphorylation at labor. The functional significance of these changes was demonstrated in vitro where myometrial strips stimulated to contract with oxytocin exhibited increased Hsp27-Ser15 phosphorylation (MacIntyre et al. 2008). Overexpression of Hsp27 in transgenic mice (Efthymiou et al. 2004) was found to protect the myocardium by reducing infarct size after ischemic injury. Thus, increased activation of both p38-MAPK and Hsp27 protein observed in the present study may indicate involvement of these proteins in cardioprotective potential of oxytocin. Moreover, increased activation of p38-MAPK pathway may be, at least partially, responsible for oxytocin-induced increase in the heart weight without apparent enhancement of cell proliferation observed in our previous study (Ondrejcakova et al. 2010).

Kobayashi et al. (2009) demonstrated an increase in phosphorylated ERK in the hearts of rabbits injected with oxytocin postinfarction. Present experiments in rats failed to demonstrate an influence of oxytocin treatment on the activation of ERKs, which play an important role in cell proliferation and differentiation. It appears that administration of oxytocin has no influence on ERK pathway and MMP-2 under physiological conditions.

The results of the present study show that prolonged treatment of rats with oxytocin leads to increased levels of ANP in the left heart ventricle. This is consistent with the findings of Gutkowska et al. (2000), showing the ability of oxytocin to release ANP from isolated perfused hearts. The mentioned authors have suggested that ANP is involved in the mediation of oxytocin action on the heart (Gutkowska et al. 1997). On the other hand, prolonged treatment with oxytocin postinfarction reduced the expression of atrial and brain natriuretic peptides in the infarcted ventricle, as well as the concentration of both peptides in the circulation (Jankowski et al. 2010). Based on present data it may be suggested that increased levels of ANP in the left ventricle induced by oxytocin treatment are mediated through activation of Akt kinase signaling pathway. This suggestion is supported also by the results of a recent study showing contribution of activated (phosphorylated) Akt kinase to enhanced expression of ANP in left ventricular cardiomyocytes (Horikawa et al. 2011).

Present study shows that prolonged oxytocin treatment improved postischemic recovery of functional parameters of the heart and led to the reduction of the infarct size. The observed changes in the above mentioned pathways indicate their potential role in oxytocin-mediated protection of the heart against ischemia/reperfusion injury that has not yet been demonstrated in vivo. As stated above, there are no reports on the effects of prolonged pretreatment of rats with oxytocin on the size of myocardial infarction. Single injection of oxytocin in anesthetized rats prior to regional myocardial ischemia provided myocardial protection against reperfusion injury by decreasing infarct size (Houshmand et al. 2009; Alizadeh et al. 2010). However, in these studies, no significant differences were observed between the control and oxytocintreated rats during reperfusion in the hemodynamic parameters measured with the exception of a significant increase in rate-pressure product. Apparently, oxytocin treatment can induce positive effects on the heart even when it is administered at the time or after the exposure to ischemia (Kobayashi et al. 2009; Jankowski et al. 2010). It may be argued that long-term treatment with oxytocin has influence on oxytocin receptors. Indeed, prolonged administration of oxytocin can result in up-regulation of oxytocin receptor mRNA (Ahmed et al. 2011). It is not contradictory to the conclusions of the present study because activation of oxytocin receptors induced by oxytocin treatment was associated with positive effects on the heart (Kobayshi et al. 2009).

It should be underlined that the dose of oxytocin and the treatment schedule used in the present study were the same in our previous experiments (Ondrejcakova et al. 2010) which demonstrated that the resulting plasma oxytocin levels are approaching those which may be observed during intensive stress situations. We hypothesize that similarly as shown for acute stress stimuli (Moghimian et al. 2011), oxytocin released during chronic stress ameliorates the negative consequences of stress on the heart.

In conclusion, prolonged treatment with oxytocin under physiological conditions in vivo leads to activation of $\mathrm{p} 38$ MAPK and PI3K/Akt kinase, reduction of the infarct size and improved postischemic recovery of heart function. The present results show that positive effects of oxytocin that may ameliorate negative consequences of stress on the heart are, at least in part, mediated through p38-MAPK and Akt kinase pathways.

Acknowledgments. This study was supported by the grants of SASNSC JRP 2010/07 and national scientific grant agency VEGA $(2 / 0118 / 11,2 / 0205 / 09$ and 2/0054/11). The authors would like to thank Iveta Blazickova, Iveta Formankova, Jana Blaskova, Ludmila Zilava and Dezider Pancza for their kind help.

\section{References}

Ahmed M. A., Elosaily G. M. (2011): Role of oxytocin in deceleration of early atherosclerotic inflammatory processes in adult male rats. Int. J. Clin. Exp. Med. 4, 169-178 
Alizadeh A. M., Faghihi M., Sadeghipour H. R., Mohammadghasemi F., Imani A., Houshmand F., Khori V. (2010): Oxytocin protects rat heart against ischemia-reperfusion injury via pathway involving mitochondrial ATP-dependent potassium channel. Peptides 31, 1341-1345 http://dx.doi.org/10.1016/j.peptides.2010.04.012

Bakos J., Bobryshev P., Tillinger A., Kvetnansky R., Jezova D. (2008): Phenylethanolamine $\mathrm{N}$-methyltransferase gene expression in the heart and blood pressure response to oxytocin treatment in rats exposed to voluntary wheel running. Ann. N.Y. Acad. Sci. 1148, 302-307 http://dx.doi.org/10.1196/annals.1410.031

Barancik M., Htun P., Strohm C., Kilian S., Schaper W. (2000): Inhibition of the cardiac p38-MAPK pathway by SB203580 delays ischemic cell death. J. Cardiovasc. Pharmacol. 35, 474-483 http://dx.doi.org/10.1097/00005344-200003000-00019

Bradford M. M. (1976): A rapid and sensitive method for the quantitation of microgram quantities of protein utilizing the principle of protein-dye binding. Anal. Biochem. 72, 248-254 http://dx.doi.org/10.1016/0003-2697(76)90527-3

Burns P. D., Mendes J. O. Jr., Yemm R. S., Clay C. M., Nelson S. E., Hayes S. H., Silvia W. (2001): Cellular mechanisms by which oxytocin mediates ovine endometrial prostaglandin F2alpha synthesis: role of $\mathrm{G}(\mathrm{i})$ proteins and mitogen-activated protein kinases. Biol. Reprod. 65, 1150-1155

http://dx.doi.org/10.1095/biolreprod65.4.1150

Cattaneo M. G., Chini B., Vicentini L. M. (2008): Oxytocin stimulates migration and invasion in human endothelial cells. Br. J. Pharmacol. 153, 728-736 http://dx.doi.org/10.1038/sj.bjp.0707609

Cattaneo M. G., Lucci G., Vicentini L. M. (2009): Oxytocin stimulates in vitro angiogenesis via a Pyk-2/Src-dependent mechanism. Exp. Cell Res. 315, 3210-3219 http://dx.doi.org/10.1016/j.yexcr.2009.06.022

Costa-E-Sousa R. H., Pereira-Junior P. P., Oliveira P. F., Olivares E. L., Werneck-de-Castro J. P., Mello D. B., Nascimento J. H., Campos-de-Carvalho A. C. (2005): Cardiac effects of oxytocin: is there a role for this peptide in cardiovascular homeostasis? Regul. Pept. 132, 107-112 http://dx.doi.org/10.1016/j.regpep.2005.09.011

Devost D., Wrzal P., Zingg H. H. (2008): Oxytocin receptor signalling. Prog. Brain Res. 170, 167-176 http://dx.doi.org/10.1016/S0079-6123(08)004

Düşünceli F., Işeri S. O., Ercan F., Gedik N., Yeğen C., Yeğen B. C. (2008): Oxytocin alleviates hepatic ischemia-reperfusion injury in rats. Peptides 29, 1216-1222 http://dx.doi.org/10.1016/j.peptides.2008.02.010

Eckertova M., Ondrejcakova M., Krskova K., Zorad S., Jezova D. (2011): Subchronic treatment of rats with oxytocin results in improved adipocyte differentiation and increased gene expression of factors involved in adipogenesis. Br. J. Pharmacol. 162, 452-463 http://dx.doi.org/10.1111/j.1476-5381.2010.01037.x

Efthymiou C. A., Mocanu M. M., de Belleroche J., Wells D. J., Latchmann D. S., Yellon D. M. (2004): Heat shock protein 27 protects the heart against myocardial infarction. Basic Res. Cardiol. 99, 392-394 http://dx.doi.org/10.1007/s00395-004-0483-6
Gutkowska J., Jankowski M., Lambert C., Mukaddam-Daher S., Zingg H. H., McCann S. M. (1997) Oxytocin releases atrial natriuretic peptide by combining with oxytocin receptors in the heart. Proc. Natl. Acad. Sci. U.S.A. 94, 11704-11709 http://dx.doi.org/10.1073/pnas.94.21.11704

Gutkowska J., Jankowski M., Mukaddam-Daher S., McCann S. M. (2000): Oxytocin is a cardiovascular hormone. Braz. J. Med. Biol. Res. 33, 625-633 http://dx.doi.org/10.1590/S0100-879X2000000600003

Hausenloy D. J., Mocanu M. M., Yellon D. M. (2004): Cross-talk between the survival kinases during early reperfusion: its contribution to ischemic preconditioning. Cardiovasc. Res. 63, 305-312 http://dx.doi.org/10.1016/j.cardiores.2004.04.011

Hlavacova N., Jezova D. (2008): Chronic treatment with the mineralocorticoid hormone aldosterone results in increased anxiety-like behavior. Horm. Behav. 54, 90-97 http://dx.doi.org/10.1016/j.yhbeh.2008.02.004

Horikawa Y. T., Panneerselvam M., Kawaraguchi Y., Tsutsumi Y. M., Ali S., Balijepalli R. C., Murray F., Head B. P., Niesman I. R., Rieg T., Vallon V., Insel P. A., Patel H. H., Roth D. M. (2011): Cardiac-specific overexpression of caveolin-3 attenuates cardiac hypertrophy and increases natriuretic peptide expression and signaling. J. Am. Coll. Cardiol. 57, 2273-2283 http://dx.doi.org/10.1016/j.jacc.2010.12.032

Houshmand F., Faghihi M., Zahediasl S. (2009): Biphasic protective effect of oxytocin on cardiac ischemia/reperfusion injury in anaesthetized rats. Peptides 30, 2301-2308 http://dx.doi.org/10.1016/j.peptides.2009.09.010

Jankowski M., Wang D., Hajjar F., Mukaddam-Daher S., McCann S. M., Gutkowska J. (2000): Oxytocin and its receptors are synthesized in the rat vasculature. Proc. Natl. Acad. Sci. U.S.A. 97, 6207-6211 http://dx.doi.org/10.1073/pnas.110137497

Jankowski M., Bissonauth V., Gao L., Gangal M., Wang D., Danalache B., Wang Y., Stoyanova E., Cloutier G., Blaise G., Gutkowska J. (2010): Anti-inflammatory effect of oxytocin in rat myocardial infarction. Basic Res. Cardiol. 105, 205-218 http://dx.doi.org/10.1007/s00395-009-0076-5

Jezova D., Skultetyova I., Tokarev D. I., Bakos P., Vigas M. (1995): Vasopressin and oxytocin in stress. Ann. N.Y. Acad. Sci. 771, 192-203 http://dx.doi.org/10.1111/j.1749-6632.1995.tb44681.x

Kobayashi H., Yasuda S., Bao N., Iwasa M., Kawamura I., Yamada Y., Yamaki T., Sumi S., Ushikoshi H., Nishigaki K., Takemura G., Fujiwara T., Fujiwara H., Minatoguchi S. (2009): Postinfarct treatment with oxytocin improves cardiac function and remodeling via activating cell-survival signals and angiogenesis. J. Cardiovasc. Pharmacol. 54, 510-509 http://dx.doi.org/10.1097/FJC.0b013e3181bfac02

MacIntyre D. A., Tyson E. K., Read M., Smith R., Yeo G., Kwek K., Chan E. C. (2008): Contraction in human myometrium is associated with changes in small heat shock proteins. Endocrinology 149, 245-252 http://dx.doi.org/10.1210/en.2007-0662

Miyamoto S., Murphy A. N., Brown J. H. (2009): Akt mediated mitochondrial protection in the heart: metabolic and survival pathways to the rescue. J. Bioenerg. Biomembr. 41, 169-180 
http://dx.doi.org/10.1007/s10863-009-9205-y

Mocanu M. M., Baxter G. F., Yue Y., Critz S. D., Yellon D. M. (2000):

The p38 MAPK inhibitor, SB203580, abrogates ischaemic preconditioning in rat heart but timing of administration is critical. Basic Res. Cardiol. 95, 472-478 http://dx.doi.org/10.1007/s003950070023

Moghimian M., Faghihi M., Karimian S. M., Imani A. (2011): The effect of acute stress exposure on ischemia and reperfusion injury in rat heart: role of oxytocin. Stress (in press) http://dx.doi.org/10.3109/10253890.2011.630436

Ondrejcakova M., Ravingerova T., Bakos J., Pancza D., Jezova D. (2009): Oxytocin exerts protective effects on in vitro myocardial injury induced by ischemia and reperfusion. Can J. Physiol. Pharmacol. 87, 137-142 http://dx.doi.org/10.1139/Y08-108

Ondrejcakova M., Bakos J., Garafova A., Kovacs L., Kvetnansky R., Jezova D. (2010): Neuroendocrine and cardiovascular parameters during simulation of stress-induced rise in circulating oxytocin in the rat. Stress 13, 314-322 http://dx.doi.org/10.3109/10253891003596822

Ravingerova T., Barancik M., Strniskova M. (2003): Mitogenactivated protein kinases: a new therapeutic target in cardiac pathology. Mol. Cell. Biochem. 247, 127-138 http://dx.doi.org/10.1023/A:1024119224033

Ravingerova T., Matejikova J., Neckar J., Andelova E., Kolar F. (2007): Differential role of PI3K/Akt pathway in the infarct size limitation and antiarrhythmic protection in the rat heart. Mol. Cell. Biochem. 297, 111-120 http://dx.doi.org/10.1007/s11010-006-9335-z

Schönbeck U., Mach F., Sukhova G. K., Murphy C., Bonnefoy J. Y., Fabunmi R. P., Libby P. (1997): Regulation of matrix metalloproteinase expression in human vascular smooth muscle cells by T lymphocytes: a role for CD40 signaling in plaque rupture? Circ. Res. 81, 448-454 http://dx.doi.org/10.1161/01.RES.81.3.448

Simoncikova P., Ravingerova T., Barancik M. (2008): The effect of chronic doxorubicin treatment on mitogen-activated protein kinases and heat stress proteins in rat hearts. Physiol. Res. 57, S97-102

Spanikova A., Ivanova M., Matejikova J., Ravingerova T., Barancik M. (2010): Influence of ischemia/reperfusion and modulation of PI3K/Akt kinase pathway on matrix metalloproteinase-2 in rat hearts. Gen. Physiol. Biophys. 29, 31-40 http://dx.doi.org/10.4149/gpb_2010_01_31

Strniskova M., Ravingerova T., Neckar J., Kolar F., Pastorekova S., Barancik M. (2006): Changes in the expression and/or activation of regulatory proteins in rat hearts adapted to chronic hypoxia. Gen. Physiol. Biophys. 25, 25-41

Thibonnier M., Conarty D. M., Preston J. A., Plesnicher C. L., Dweik R. A., Erzurum S. C. (1999): Human vascular endothelial cells express oxytocin receptors. Endocrinology 140, 1301-1309 http://dx.doi.org/10.1210/en.140.3.1301

Tuğtepe H., Sener G., Biyikli N. K., Yüksel M., Cetinel S., Gedik N., Yeğen B. C. (2007): The protective effect of oxytocin on renal ischemia/reperfusion injury in rats. Regul. Pept. 140, 101-108 http://dx.doi.org/10.1016/j.regpep.2006.11.026

Yue Y., Qin Q., Cohen M. V., Downey J. M., Critz S. D. (2002): The relative order of $\mathrm{mK}(\mathrm{ATP})$ channels, free radicals and $\mathrm{p} 38$ MAPK in preconditioning's protective pathway in rat heart. Cardiovasc. Res. 55, 681-689 http://dx.doi.org/10.1016/S0008-6363(02)00452-2

Received: November 24, 2011

Final version accepted: February 7, 2012 